OPEN

SUBJECT AREAS:

ELECTRONIC PROPERTIES

AND MATERIALS

THERMOELECTRICS

Received

2 October 2013

Accepted

18 November 2013

Published

13 December 2013

Correspondence and requests for materials should be addressed to S.R.W. (shiren.wang@ Hu.edu)

\footnotetext{
* These authors contributed equally to this work.
}

\section{Enhancing thermoelectric properties of organic composites through hierarchical nanostructures}

\author{
Kun Zhang*, Yue Zhang* \& Shiren Wang
}

Nanomaterials and Nanomanufacturing Laboratory, Department of Industrial Engineering, Whitacre College of Engineering, Texas Tech University, Lubbock TX.

Organic thermoelectric (TE) materials are very attractive due to easy processing, material abundance, and environmentally-benign characteristics, but their potential is significantly restricted by the inferior thermoelectric properties. In this work, noncovalently functionalized graphene with fullerene by $\pi-\pi$ stacking in a liquid-liquid interface was integrated into poly(3,4-ethylenedioxythiophene) poly(styrenesulfonate). Graphene helps to improve electrical conductivity while fullerene enhances the Seebeck coefficient and hinders thermal conductivity, resulting in the synergistic effect on enhancing thermoelectric properties. With the integration of nanohybrids, the electrical conductivity increased from $\sim 10000$ to $\sim 70000 \mathrm{~S} / \mathrm{m}$, the thermal conductivity changed from 0.2 to $2 \mathrm{~W} \cdot \mathrm{K}^{-1} \mathrm{~m}^{-1}$ while the Seebeck coefficient was enhanced by around 4 -fold. As a result, nanohybrids-based polymer composites demonstrated the figure of merit $(\mathrm{ZT})$ as high as $6.7 \times 10^{-2}$, indicating an enhancement of more than one order of magnitude in comparison to single-phase filler-based polymer composites with ZT at the level of $10^{-3}$.

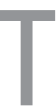
hermoelectric materials are expected to play an increasingly important role in power generation, solid-state cooling, and heating systems ${ }^{1}$. The performance of thermoelectric materials is characterized by a dimensionless figure of merit $\mathrm{ZT}=\mathrm{S}^{2} \sigma \mathrm{T} / \kappa$, where $\mathrm{S}, \sigma, \kappa$, T represents the Seebeck coefficient $(\mu \mathrm{V} / \mathrm{K})$, electrical conductivity $(\mathrm{S} / \mathrm{cm})$, thermal conductivity $(\mathrm{W} / \mathrm{m} . \mathrm{K})$, and absolute temperature $(\mathrm{K})$, respectively ${ }^{1-3}$. A high ZT is required for efficient conversion of thermal and electrical energy. Hence, high $S$, high $\sigma$ and low $\kappa$ is required for high ZT. However, there exist challenging conflicts between the electrical conductivity and the Seebeck coefficient or thermal conductivity. Generally, increasing $S$ results in decreasing $\sigma$ while increasing $\sigma$ increases $\kappa$. Recently, two strategies have been proposed to enhance the thermoelectric properties, including (i) the reduction of lattice thermal conductivity by involving phonon scattering ${ }^{4-6}$; ii) enhancing the thermoelectric power factor $\mathrm{S}^{2} \sigma$ by quantum confinement ${ }^{7-10}$, energy filtering ${ }^{11-13}$, or tuning the electronic band structure (i.e. the density of states $)^{14-15}$. The incorporation of lower-dimensional structures could create sharp features in electronic density of state, and thus result in the increased asymmetry of the differential conductivity with respect to the Fermi energy ${ }^{16}$.

Polymers are very attractive to exploit next-generation thermoelectric materials due to their low-cost, lightweight, facile processability, and environmentally-benign characteristics ${ }^{3}$. Their relatively low thermal conductivity provides an effective strategy to improve thermoelectric performance. However, their electrical conductivity is too low. Highly doped polymer could show high electrical conductivity, but their Seebeck coefficient is compromised, resulting in very low ZT. In order to address this demand, conjugated polymer composites currently receive more and more attentions. Polymer composites are very attractive for thermoelectric applications since it is cost-effective to tune the composite interface for decoupling the aforementioned conflicts. Organic fillers, like carbon nanotubes (CNTs) as conductive fillers were added into conjugated polymers, for instance, polyaniline (PANI), poly(3,4-ethylenedioxythiophene) poly(styrenesulfonate) (PEDOT:PSS), to create CNTpolymer interfaces for enhancing thermoelectric properties. The formed interfaces were considered to effectively introduce energy filtering, or phonon scattering. In situ growth of PANI using the CNT network template resulting in CNT-PANI core-shell nanostructures was investigated and the ZT was $\sim 0.004$ due to the increased electrical conductivity and Seebeck coefficient ${ }^{17}$. Porous CNT-PANI core-shell nanostructures were also reported with improved thermoelectric properties via enhanced phonon scattering and increased power factor $\left(S^{2} \sigma\right)$, resulting in a $\mathrm{ZT}$ of $0.01^{18}$. Additionally, some other attempts have been made to wrap single-walled carbon 
nanotubes (SWNTs) using special semiconducting stabilizers and then dispersed them into a polymer matrix, resulting in electrically connected and thermally disconnected network, indicating promoted electrical transport with disrupted thermal transport. Emulsion-stabilized SWNT-composites showed a ZT up to 0.006 at a SWNT loading of $20 \mathrm{wt} \%$, and PEDOT:PSS stabilized-SWNT composites showed a ZT of 0.02 at a SWNT loading of $35 \mathrm{wt} \%^{19,20}$. Similar to CNTs, graphene has also been integrated into the polymer composites for thermoelectric applications ${ }^{21-24}$. Physical mixing or in situ polymerization has been used to fabricate graphene composites. Although the incorporation of graphene into polymers slightly improved thermoelectric properties, the aforementioned conflicts between electrical conductivity and thermal conductivity, or the Seebeck coefficient remain unsolved. In brief, unitary fillers incorporating into polymers prefer either simply improving power factor or reducing thermal conductivity. Herein, the authors proposed that it would be more effective to employ hybrid nanocarbon fillers to engineer alternative organic thermoelectric materials with competitive performance.

Fullerene has been reported with the absolute Seebeck coefficient of $\sim 2000 \mu \mathrm{V} / \mathrm{K}$ at $300 \mathrm{~K}^{25}$. The thermal conductivity of fullerene is $\sim 0.16 \mathrm{~W} / \mathrm{m} \cdot \mathrm{K}^{26}$. According to recent studies, fullerene has been used to reduce the thermal conductivity and thus improve their thermoelectric performance ${ }^{27-30}$.The increased phonon scattering may result in decreased lattice thermal conductivity. However, to the best of the authors' knowledge, there have been no reports on integrating fullerene-functionalized graphene into conjugated polymers for enhancing thermoelectric properties.

In this work, we noncovalently functionalized graphene with semiconducting fullerene, and then integrated fullerene-decorated graphene into a conjugated polymer, PEDOT:PSS. It was found that tailoring the fullerene and graphene ratio helps to increase the composite electrical conductivity much faster than the thermal conductivity due to the significant interfacial phonon scattering. The Seebeck coefficient was enhanced by as high as 4 -fold due to interfacial energy filtering. The highest ZT, 0.067 , was achieved for $30 \mathrm{wt} \%$ nanohybrids-filled polymer composite where the ratio of fullerene to graphene was $3: 7$.

\section{Results}

The noncovalent functionalization of reduced graphene oxide (rGO) by fullerene $\left(\mathrm{C}_{60}\right)$ was realized by $\pi-\pi$ stacking in the liquid-liquid interface. Briefly, a certain amount of $\mathrm{rGO}$ /isopropanol (IPA) solution was gently injected into $\mathrm{C}_{60} / \mathrm{m}$-xylene solution. An apparent dark green interface was observed in between two liquid mediums, indicating the formation of $\mathrm{C}_{60}$ and graphene hybrids. The rGO in IPA and $\mathrm{C}_{60}$ in $\mathrm{m}$-xylene continuously diffuse from their own solutions into the interface between these two liquids because of the concentration gradient. The assembly of $\mathrm{C}_{60}$ on rGO surface occurred when they meet each other in the interfacial area by $\pi-\pi$ interaction. By continuously extracting the interface solution, sufficient fullerene-decorated rGO can be collected for further usage.

As-prepared $\mathrm{rGO}$ and $\mathrm{C}_{60} / \mathrm{rGO}$ hybrid were characterized by transmission electron microscope (TEM), as shown in Figure 1. The rGO shows a smooth surface and no particles on its surface are observed. The $\mathrm{C}_{60}$-decorated graphene samples prepared using $0.5,0.75,1$ and $2 \mathrm{mg} / \mathrm{ml} \mathrm{C}_{60}$ solution show some dark nanoparticles (NPs), which should be $\mathrm{C}_{60}$ clusters. However, no $\mathrm{C}_{60}$ nanoparticles are observed on the surface of the $\mathrm{C}_{60} / \mathrm{rGO}$ hybrid fabricated with $0.1 \mathrm{mg} / \mathrm{ml} \mathrm{C}_{60}$ solution. This might be due to that the concentration gradient of the $\mathrm{C}_{60} / \mathrm{m}$-xylene solution is too small to facilitate the diffusion, and thus no NPs were formed after adding another liquid phase. At higher concentrations, the concentration gradient drives the diffusion significantly and resulted in assembly on the liquidliquid interface. Smaller $\mathrm{C}_{60}$ nanoparticles are spherical while larger nanoparticles possess variable shapes, which might arise from the agglomeration of small spheres ${ }^{31-34}$. Most strikingly, graphene layers without $\mathrm{C}_{60}$ molecules tend to restack due to the interlayer $\pi-\pi$ interaction, forming few-layered graphene (Figure $1 \mathrm{~b}$ ). On the other hand, the $\mathrm{C}_{60} / \mathrm{rGO}$ samples showed single or few layered structures, which might stem from the attached $\mathrm{C}_{60}$ particles, which efficiently prevents the restacking and agglomeration of graphene layers during processing in solution. The particle size distribution of the assembled $\mathrm{C}_{60}$ was investigated based on the measurement of $\mathrm{C}_{60}$ clusters and was shown in Figure 2 and Figure S1 (Supplementary Materials). When a $0.5 \mathrm{mg} / \mathrm{ml} \mathrm{C}_{60}$ solution was used, the average particle size is $13 \mathrm{~nm}$. Higher $\mathrm{C}_{60}$ concentrations result in larger particles and reach 23,26 and $32 \mathrm{~nm}$ for $0.75,1$ and $2 \mathrm{mg} / \mathrm{ml}$, respectively. The increased particle size should result from the higher $\mathrm{C}_{60}$ concentration, which tends to form larger seeds for nanoparticle growth. Since changing $\mathrm{C}_{60}$ concentration from 0.75 to $1 \mathrm{mg} / \mathrm{ml}$ has little effect on the seed size, no obvious difference on $\mathrm{C}_{60}$ nanoparticle size was observed when the $\mathrm{C}_{60}$ concentration was increased from $0.75 \mathrm{mg} /$ $\mathrm{ml}$ to $1 \mathrm{mg} / \mathrm{ml}$. Additionally, $\mathrm{C}_{60}$-decorated $\mathrm{rGO}$, which was fabricated at a higher $\mathrm{C}_{60}$ concentration, shows wider size distribution of $\mathrm{C}_{60}$ in comparison to that fabricated at a lower concentration. In the initial period of $\mathrm{C}_{60}$ nanoparticle seed formation, the $\mathrm{C}_{60}$ solution suffers from concentration depletion immediately after the nucleation at the interface $e^{35,36}$. The anti-solvent diffused gradually into
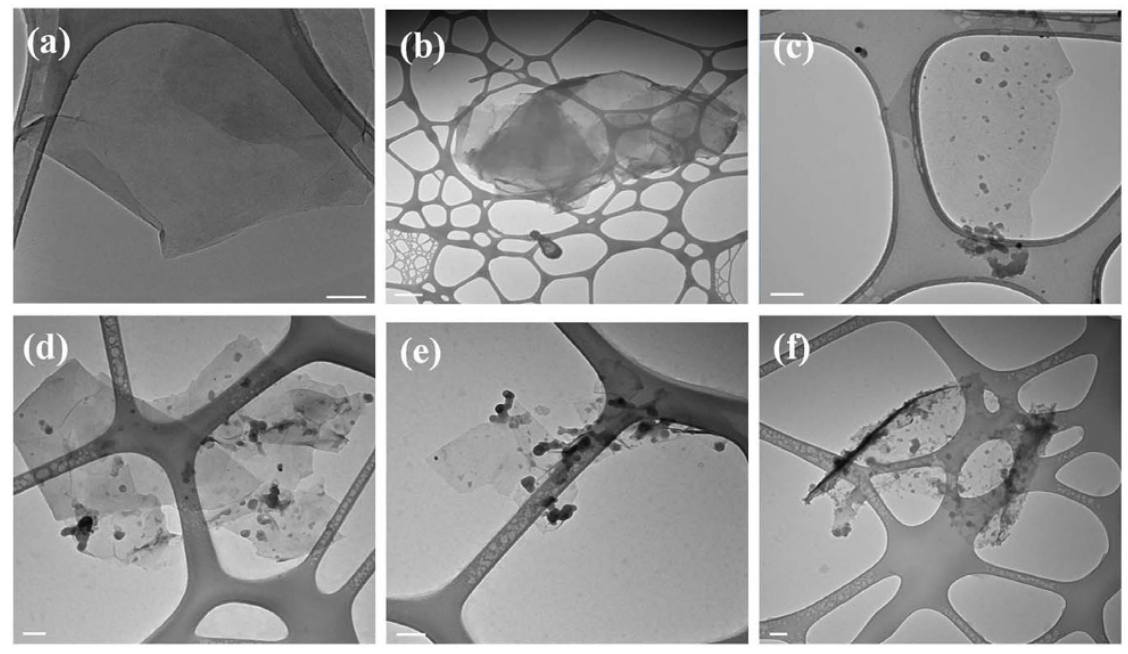

Figure 1 TEM images of graphene (a) and $\mathrm{C}_{60} /$ graphene hybrid fabricated using $0.1 \mathrm{mg} / \mathrm{ml}(\mathrm{b}), 0.5 \mathrm{mg} / \mathrm{ml}(\mathrm{c}), 0.75 \mathrm{mg} / \mathrm{ml}(\mathrm{d}), 1 \mathrm{mg} / \mathrm{ml}(\mathrm{e}) \mathrm{and} 2 \mathrm{mg} /$ $\mathrm{ml}(\mathrm{f}) \mathrm{C}_{60}$ solution. (Scale bar: $100 \mathrm{~nm}$ ). 


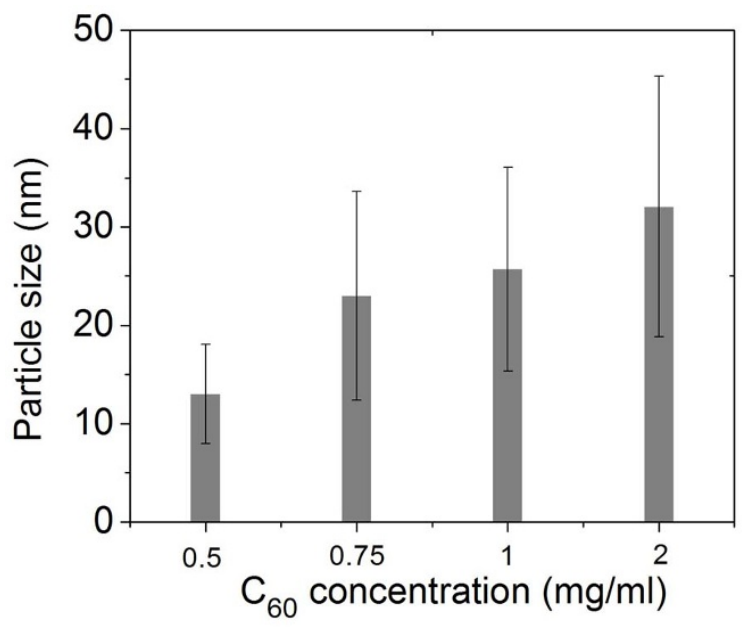

Figure $2 \mid$ Size of $\mathrm{C}_{60}$ cluster at $\mathrm{C}_{60} / \mathrm{rGO}$ hybrids as a function of initial $\mathrm{C}_{60}$ concentration.

the interlayer, thus a $\mathrm{C}_{60}$ concentration gradient was formed within the interlayer, which may induce a wide seed size distribution. A higher initial $\mathrm{C}_{60}$ concentration tends to have a greater concentration gradient followed with a wider size distribution of the $\mathrm{C}_{60}$ nanoparticles. It has been reported that other factors, such as the drowningout ratio (anti-solvent/solvent volume ratios), solvent type, and anti-solvent type can influence the morphology of nanoparticles ${ }^{37}$. This may provide effective approaches to further tune the size of $\mathrm{C}_{60}$ nanoparticles.

The $\mathrm{rGO}$ and $\mathrm{C}_{60} / \mathrm{rGO}$ samples were characterized by XRD and Raman spectra, as shown in Figure 3 and Figure 4, respectively. In Figure 3, the (002) peak at $27^{\circ}$ for pristine graphite indicates an interlayer spacing of $0.34 \mathrm{~nm}$. The (002) peak of graphene oxide (GO) is shifted to $14.6^{\circ}$, indicating that the interlayer spacing increases to $0.72 \mathrm{~nm}$ after oxidization ${ }^{38}$. After chemical reduction by hydrazine, the sharp (002) peak of graphite oxide disappeared while another broad peak of around $24^{\circ}$ shows up. The disappearance of the sharp peak can be attributed to the exfoliation of layered structures of graphite oxide. The broad peak may stem from the partial restacking of exfoliated graphene layers. $\mathrm{C}_{60} / \mathrm{rGO}$ hybrids show characteristic peaks of $\mathrm{C}_{60}$ at $10.8^{\circ}, 17.7^{\circ}, 20.8^{\circ}, 21.7^{\circ}, 27.5^{\circ}$ and $28.2^{\circ}$ corresponding to the (111), (220), (311), (222), (331) and (420) diffraction of $\mathrm{C}_{60}$, respectively ${ }^{39}$. The broad diffraction of graphene in the range of $22^{\circ}$ to $26^{\circ}$ disappeared and this might be

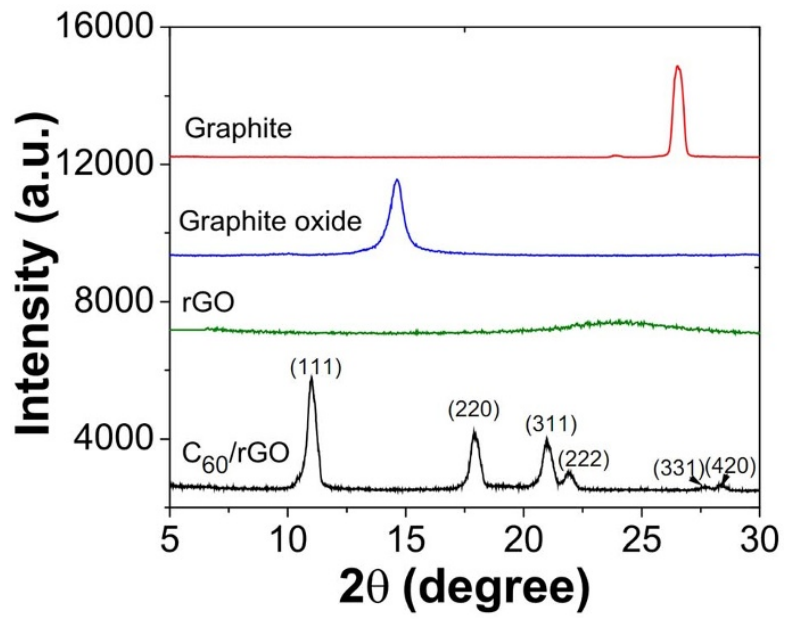

Figure $3 \mid \mathrm{XRD}$ patterns of graphite, graphite oxide, reduced graphene oxide and $\mathrm{C}_{60} / \mathrm{rGO}$ hybrid.

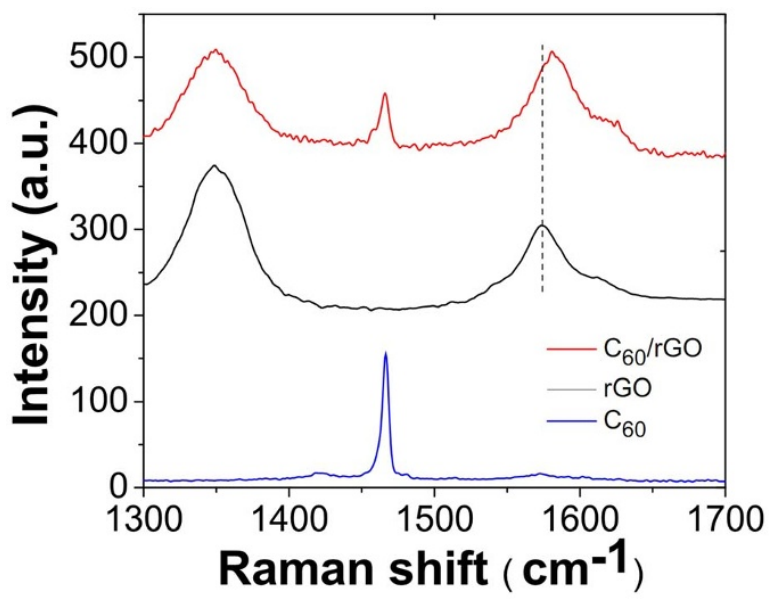

Figure $4 \mid$ Raman spectra of $\mathrm{C}_{60}, \mathrm{rGO}$ and $\mathrm{C}_{60} / \mathrm{rGO}$ hybrid.

attributed to the assembled $\mathrm{C}_{60}$ clusters, which effectively prevented the restacking of the graphene layers. The X-ray diffraction (XRD) patterns indicate that fullerenes had been successfully incorporated onto the surface of graphene and they worked as spacers to keep the individual graphene sheets from restacking.

Raman spectroscopy is a fast and non-destructive technique to provide insight on the electronic and lattice structures of carbon materials ${ }^{40}$. Raman spectra of the graphene, pristine $\mathrm{C}_{60}$, and $\mathrm{C}_{60}$ / graphene were shown in Figure 4. The rGO shows an intense G-band ( $s p^{2}$ carbon) at $1576 \mathrm{~cm}^{-1}$ which corresponds to the $\mathrm{Eg}^{2}$ phonon at the centre of the Brillouin zone $e^{41}$. The D-band ( $s p^{3}$ carbon) at $1348 \mathrm{~cm}^{-1}$ comes from the out-of-plane breathing mode of the $s p^{2}$ carbons, which is due to the presence of defects that were introduced in oxidization and reduction procedure ${ }^{42}$. The sharp peak at $1466 \mathrm{~cm}^{-1}$ indicates the pentagonal pinch mode $\mathrm{A}_{\mathrm{g}}(2)$ of $\mathrm{C}_{60}$ molecules $^{43}$. The $\mathrm{C}_{60} / \mathrm{rGO}$ hybrid demonstrated three Raman peaks at $1344 \mathrm{~cm}^{-1}, 1467 \mathrm{~cm}^{-1}, 1582 \mathrm{~cm}^{-1}$, corresponding to the $\mathrm{D}$ band (1344 $\left.\mathrm{cm}^{-1}\right), \mathrm{G}$ band $\left(1582 \mathrm{~cm}^{-1}\right)$ of graphene, and the pentagonal pinch mode of $\mathrm{C}_{60}$ molecules $\left(1467 \mathrm{~cm}^{-1}\right)$, respectively. Moreover, the $\mathrm{G}$ band for graphene $\left(1575 \mathrm{~cm}^{-1}\right)$ upshifts to $1582 \mathrm{~cm}^{-1}$ in the $\mathrm{C}_{60}$ /graphene hybrid, indicating a charge-transfer from the graphene to $\mathrm{C}_{60}{ }^{44}$. Based on the Raman results, it is confirmed that $\mathrm{C}_{60}$ were successfully assembled onto graphene and the charge-transfer occurred between graphene and $\mathrm{C}_{60}$ molecules.

The UV-Vis spectra of $\mathrm{C}_{60}$ and $\mathrm{C}_{60} / \mathrm{rGO}$ were collected by illuminating $\mathrm{C}_{60}$ and $\mathrm{C}_{60} / \mathrm{rGO}$ solutions, respectively. As shown in Figure 5, the spectrum of the $C_{60}$ shows two characteristic peaks at

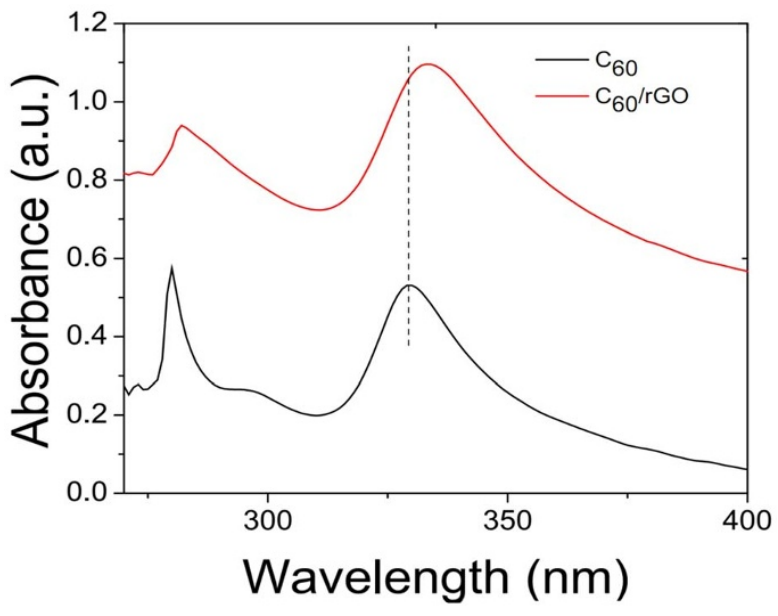

Figure $5 \mid \mathrm{UV}$-Vis spectra of $\mathrm{C}_{60}$ and $\mathrm{C}_{60} / \mathrm{rGO}$ hybrid in solution. 

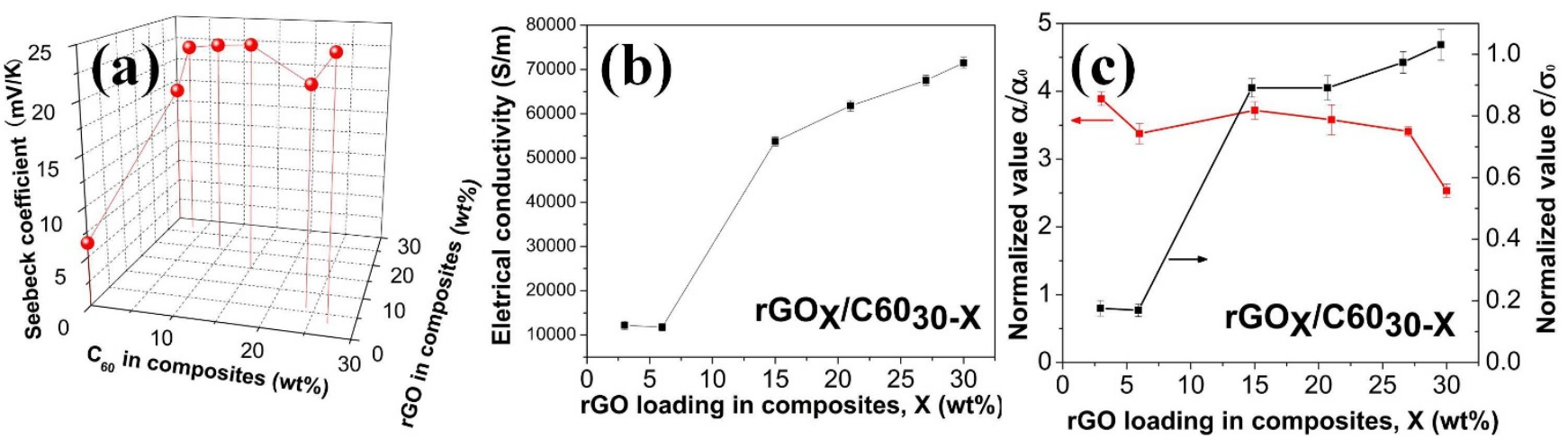

Figure $6 \mid$ (a) Three-dimensional plot of the Seebeck coefficient of composites as a function of $\mathrm{C}_{60}$ and rGO weight loading in composites, indicating more than 4-fold enhancement. (Table S1 shows the Seebeck coefficients with error bars.) (b) The electrical conductivity of nanohybrids-filled polymer composites. (c) Normalized Seebeck coefficient and electrical conductivity to show the improvement factor. $\alpha_{0}$, $\sigma_{0}$ are the Seebeck coefficient and electrical conductivity of pure polymer matrix, respectively.

280 and $328 \mathrm{~nm}$. The peak at $328 \mathrm{~nm}$ stems from the $\pi-\pi$ electronic transitions ${ }^{45}$. The red shift of the peak at $328 \mathrm{~nm}$ is correlated with the interactions between $\mathrm{C}_{60}$ and other molecules, and thus this peak is a crucial indicator for the interaction of fullerene and aromatic rings ${ }^{46}$. The $\pi-\pi$ stacking of $\mathrm{C}_{60}$ and graphene may delocalize the $\pi$ electron system and reduce the energy for the electronic transition ${ }^{32}$. The peak at $328 \mathrm{~nm}$ in $\mathrm{C}_{60}$ shifts to $334 \mathrm{~nm}$ in the $\mathrm{C}_{60} / \mathrm{rGO}$, indicating that $\mathrm{C}_{60}$ was successfully assembled to graphene and the $\pi-\pi$ interaction significantly facilitates the formation of the as prepared $\mathrm{C}_{60} / \mathrm{rGO}$ hybrids.

In this work, the Seebeck coefficient, electrical conductivity and thermal conductivity were measured at room temperature. For the loading of $\mathrm{rGO}_{\mathrm{x}} \mathrm{C}_{6030-\mathrm{x}}$ nanohybrids in Figure 6, $x$ was the weight fraction of $\mathrm{rGO}$ while the $\mathrm{C}_{60}$ fraction was $30-x$ in the polymer composites. The Seebeck coefficients and electrical conductivities of $\mathrm{C}_{60} /$ rGO-polymer composites were plotted as a function of $x$, the rGO fraction (See Figure 6). In addition, a three-dimensional plot of Seebeck coefficients of composites was shown Figure 6(a). Moreover, the composite electrical conductivities and Seebeck coefficients were normalized by dividing the pure polymer as shown in Figure 6(c), indicating the improvement factor. The Seebeck coefficients of the rGO and neat PEDOT:PSS film are measured to be $18 \mu \mathrm{V} / \mathrm{K}$, and $6.4 \mu \mathrm{V} / \mathrm{K}$, respectively. With the incorporation of $\mathrm{C}_{60}$-decorated $\mathrm{rGO}$, the Seebeck coefficient of $\mathrm{rGO} / \mathrm{C}_{60}$-polymer composites are measured to be $24.9,21.6,23.8,22.9$, and $21.8 \mu \mathrm{V} / \mathrm{K}$ with $\mathrm{rGO}$ loading of $3 \%, 6 \%, 15 \%, 21 \%$, and $27 \%$, respectively. The PEDOT:PSS composite with $30 \mathrm{wt} \% \mathrm{rGO}$ shows its Seebeck coefficient of $16.2 \mu \mathrm{V} / \mathrm{K}$, which is close to that of $\mathrm{rGO}$, but 2 -fold larger than the neat PEDOT:PSS film. Electrical conductivities of nanohybrids/polymer composites were shown in Figure 6(b). Higher rGO loading in the composites results in higher electrical conductivity. For the loading of $\mathrm{rGO}_{\mathrm{x}} \mathrm{C}_{6030-\mathrm{x}}$ nanohybrids, when $x=3 \%$, the electrical conductivity of as-prepared composites is $12190 \mathrm{~S} / \mathrm{m}$. Increasing $x$ leads to the increased electrical conductivity, and it reaches to $71503 \mathrm{~S} / \mathrm{m}$ when $x=30 \%$. By tuning the ratio between $\mathrm{C}_{60}$ and $\mathrm{rGO}$ in the polymer composites, the highest power factor $\left(\mathrm{S}^{2} \sigma\right)$ of $32.4 \mu \mathrm{W} /$ $\mathrm{m} \cdot \mathrm{K}^{2}$ is achieved $\mathrm{x}=21 \%\left(\mathrm{C}_{60}: \mathrm{rGO}=21 \%: 9 \%=7: 3\right)$ in the asproduced composite, which is more than 10 -fold larger than the power factor of neat polymer film $\left(2.8 \mu \mathrm{W} / \mathrm{m} \cdot \mathrm{K}^{2}\right)$.

The thermal conductivity and thermoelectric figure of merit were plotted in Figure 7. Increasing $x$ results in higher thermal conductivity. Particularly, the composite thermal conductivity is significantly increased when $\mathrm{x}>21 \%$. The composite thermal conductivity is $\sim 0.2 \mathrm{Wm}^{-1} \mathrm{~K}^{-1}$ for $\mathrm{x}=21 \%$, and it reachs $0.7 \mathrm{Wm}^{-1} \mathrm{~K}^{-1}$ at $x=27 \%$, and $2.3 \mathrm{Wm}^{-1} \mathrm{~K}^{-1}$ at $x=30 \%$. ZT tended to increase as $x \leq 21 \%$, while it tended to decrease as $x>21 \%$. The highest ZT was achieved at ZT $=0.067$ when $\mathrm{x}=21 \%$ in the
$\mathrm{rGO}_{\mathrm{x}} \mathrm{C} 0_{30-\mathrm{x}}$ nanohybrid-filled polymer composites, where the ratio of $\mathrm{C}_{60}$ to $\mathrm{rGO}$ was $3: 7$.

\section{Discussion}

Graphene is a semi-metallic material with zero-bandgap ${ }^{47,48}$, but $\mathrm{C}_{60^{-}}$ decorated rGO was found to show a finite band gap dependent on the $\mathrm{C}_{60}$ functionalization degree. Incorporating as-produced nanohybrids into the conjugated polymer (PEDOT:PSS) could tune the electronic and phonon transport for tailored thermoelectric properties. Considering the processing challenges and morphology uniformity, the weight loading of $\mathrm{C}_{60}$-decorated $\mathrm{rGO}$ was set to $30 \mathrm{wt} \%$. Effects of $\mathrm{C}_{60}$ and rGO loading on the thermoelectric properties of the resultant composites were explored. The electrical conductivity, thermal conductivity and Seebeck coefficient of $\mathrm{C}_{60}$-decorated $\mathrm{rGO} /$ polymer composites were all measured at the room temperature.

With the incorporation of $\mathrm{C}_{60}$-decorated $\mathrm{rGO}$, the Seebeck coefficients of $\mathrm{rGO} / \mathrm{C}_{60}$-polymer composites show 2 -fold larger than the neat PEDOT:PSS film (Figure 6(a)). Addition of rGO in polymer should increase the carrier mobility in composites, resulting in higher electrical conductivity and higher Seebeck coefficient ${ }^{23}$. With the incorporation of $\mathrm{C}_{60} / \mathrm{rGO}$ nanohybrids, the Seebeck coefficient of the resultant composites could show as high as 4-fold improvement in comparison with that of neat PEDOT:PSS film. Higher $\mathrm{C}_{60}$ loading resulted in higher Seebeck coefficient, but would decrease the electrical conductivity. Besides the aforementioned reason, another possible reason might be that the incorporation of $\mathrm{C}_{60}$ might push the Fermi level away from the valence band, resulting in an increased Seebeck coefficient ${ }^{25,49}$. In addition, $\mathrm{C}_{60}$ nanoparticles assembled on graphene surfaces might preferentially allow highenergy carriers to pass while blocking cold-energy carriers and gen-

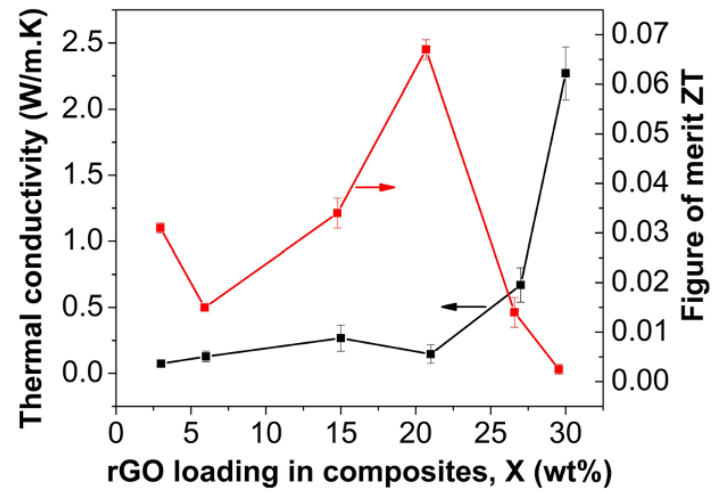

Figure 7 | Thermal conductivity and thermoelectric figure of merit ZT of nanohybrids-filled polymer composites. 


\section{PEDOT:PSS}

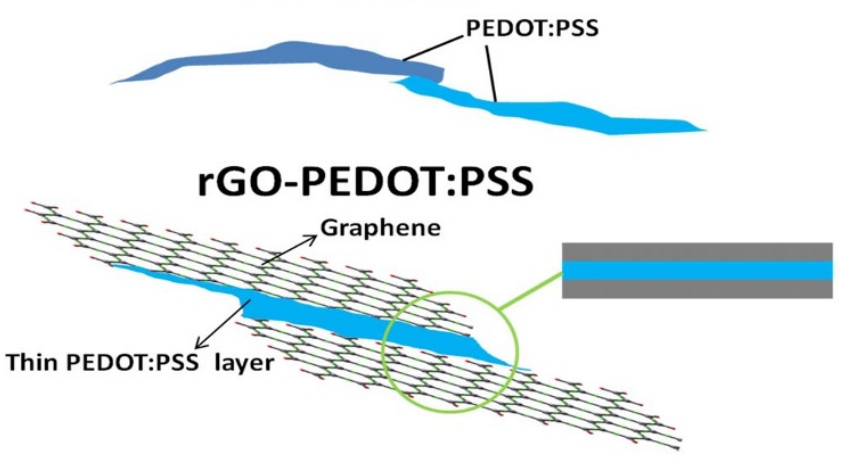

\section{C60/rGO-PEDOT:PSS}

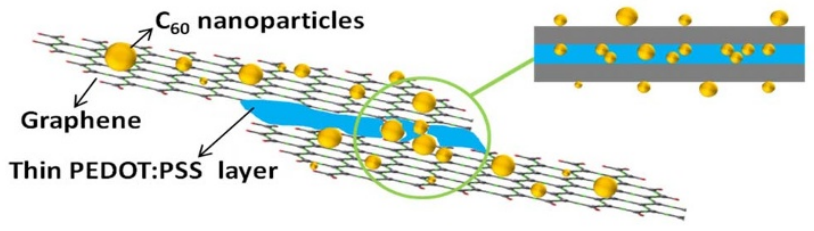

Figure $8 \mid$ Schematic illustration of carrier transport in the neat polymer film, rGO-polymer and $\mathrm{C}_{60} /$ rGO nanohybrids-filled polymer composites.

erating an energy filtering effect ${ }^{50-52}$. Hence, it will increase the mean carrier energy in carrier transport with an enhanced Seebeck coefficient ${ }^{50,51}$. Moreover, since the $\mathrm{C}_{60}$ nanoparticles are zero-dimensional nanostructures, it might be possible to allow quantum confinement during carrier transport, which will further enhance the Seebeck coefficient ${ }^{1}$.

Electrical conductivities of nanohybrids/polymer composites are shown in Figure 6(b). Higher rGO loading in the composites resulted in higher electrical conductivity. Increasing rGO loading $x$ leads to the increased electrical conductivity, and it reaches $71503 \mathrm{~S} / \mathrm{m}$ when $x=30 \%$. This should be due to the facilitated carrier mobility by the $\pi-\pi$ interactions between the graphene surface and PEDOT:PSS ${ }^{24}$. The lower electrical conductivity at lower rGO loading might be assigned to the incorporation of high-loaded $\mathrm{C}_{60}$ nanoparticles roughing rGO surfaces, leading to the significant electron scattering, disrupting electron transport in polymers. The mechanism was further illustrated in Figure 8. Since the $\mathrm{C}_{60} / \mathrm{rGO}$ hybrid weight loading in PEDOT:PSS composites was fixed to be $30 \mathrm{wt} \%$, lower rGO weight loading indicated higher $\mathrm{C}_{60}$ weight loading. The strong electron scattering involved by $\mathrm{C}_{60}$ nanoparticles will compromise the increase in electron mobility. Additionally, as aforementioned, the interaction between $\mathrm{C}_{60}$ and $\mathrm{rGO}$ was $\pi-\pi$ interaction, indicating their intimate contact. The weak contact between hybrid filler and polymer may lead to high electrical contact resistance, resulting in the decrease in electrical conductivity. Moreover, the big difference of electrical conductivity between $\mathrm{C}_{60}\left(\sim 10^{-19}-10^{-11} \mathrm{~S} / \mathrm{cm}\right)^{25}$ and rGO, or $\mathrm{C}_{60}$ and PEDOT:PSS polymers could further reduce the electrical conductivity. Due to the high electrical resistivity of $\mathrm{C}_{60}$, the composites electrical conductivity was decreased at a higher fraction of $\mathrm{C}_{60}$.

As shown in Figure 7, increasing $x$ resulted in higher thermal conductivity. Particularly, the composite thermal conductivity was significantly increased when $x>21 \%$. The rGO is highly thermal conductive and may form the percolation network in PEDOT:PSS matrix at higher loading. When $\mathrm{x}>21 \%$, the ratio of $\mathrm{C}_{60}$ to $\mathrm{rGO}$ was less than $1: 9$, and thus $\mathrm{C}_{60}$ loading fraction is too low to prevent the direct contact between neighbored rGO layers. When $\mathrm{x}<21 \%$, the ratio of $\mathrm{C}_{60}$ to $\mathrm{rGO}$ was larger than $1: 9$, and thus high loading of $\mathrm{C}_{60}$ may prevent the direct contact between neighbored $\mathrm{rGO}$, resulting in

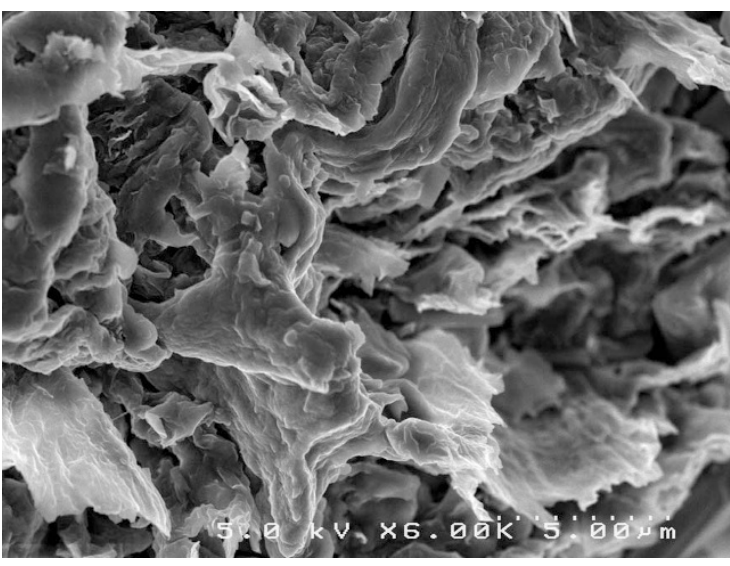

Figure 9| Typical microstructure of nanohybrid-filled polymer composites.

high thermal interfacial resistance between neighbored rGO layers ${ }^{52}$. In addition, the percolation network of rGO might be disrupted due to its low fractions. Secondly, high fraction of $\mathrm{C}_{60}$ nanoparticles also contributed low phonon transport path since $\mathrm{C}_{60}$ showed thermal conducting of $0.16 \mathrm{~W} / \mathrm{m} \cdot \mathrm{K}$. Moreover, nanoscaled $\mathrm{C}_{60}$ decoration on the graphene surface will create a rough interface between filler and matrix, resulting in significant phonon scattering and thus thermal conductivity ${ }^{17}$. As shown in Figure 2, the $\mathrm{C}_{60}$ particle size on graphene surfaces ranges from $\sim 10 \mathrm{~nm}$ to $\sim 40 \mathrm{~nm}$. Large $C_{60}$ particles scatter phonons with middle wavelengths, small $\mathrm{C}_{60}$ particles scatter phonons with short wavelengths, and thin PEDOT:PSS layers between rGO layers formed interfaces for scattering phonons with long wavelengths. For phonons which carry most of the heat, an average mean-free-path can be plausibly defined. So when the particle size matches the phonon mean free path in PEDOT:PSS, effective phonon scattering will occur according to Casimir regime ${ }^{53,54}$. The $\mathrm{C}_{60}$ nanoparticles on the surface of graphene facilitate scattering phonons with whole wavelengths, achieving a lower lattice thermal conductivity. Of course, $\mathrm{C}_{60}$-decorated graphene would also introduce porous structure due to its hydrophobic feature, and further reduced the thermal conductivity. Porous PANI composites have been reported to optimize thermoelectric ZT by reducing thermal conductivity without compromising the electrical conductivity ${ }^{18}$. A SEM image of nanohybrid composites at $\mathrm{x}=9 \%$ is shown in Figure 9, and micro-scaled pores were observed.

The ZT was also calculated as function of $x$ in the $\mathrm{rGO}_{\mathrm{x}} \mathrm{C} 60_{30-\mathrm{x}}$ nanohybrid-filled polymer composites, as shown in Figure 8. As $x \leq$ $21 \%$, ZT tended to increase, since the electrical conductivity rose much faster than the thermal conductivity, as shown in Figure 6 and 8 . When $x>21 \%$, ZT tended to decrease since the thermal conductivity of the composites increased drastically, much faster than electric conductivity. As a result, the highest $\mathrm{ZT}$ was achieved at $\mathrm{ZT}=0.067$ when $\mathrm{x}=21 \%$ in the $\mathrm{rGO}_{\mathrm{x}} \mathrm{C} 60_{30-\mathrm{x}}$ nanohybrid-filled polymer composites, where the ratio of $\mathrm{C} 60$ to $\mathrm{rGO}$ was $3: 7$. For comparison, thermoelectrics of graphene/polymer composites and fullerene/polymer composites were also investigated, respectively, but their ZT was at the level of $10^{-3}$. Therefore, the synergistic effects of graphene and $\mathrm{C}_{60}$ can balance the conflicts of the thermal/electric transport and resulted in the largest ZT in the polymer composites.

In conclusion, hierarchical fullerene-graphene nanohybrids were successfully synthesized and the structure characterizations including TEM, XRD, Raman and UV-Vis spectra have confirmed the decoration of fullerene on rGO and charge transfer between them. Subsequently, organic thermoelectric materials were fabricated by integrating such novel hierarchical nanohybrids into a conjugated polymer. In the hierarchical nanohybrid-filled polymer composites, 4 -folder improvement in the Seebeck coefficient was achieved as 
compared to the neat polymer film due to the potential interfacial energy filtering. Tuning the ratio of $\mathrm{C}_{60}$ to graphene in the nanohybrids can make electrical conductivity increment surpassed the increase in the thermal conductivity, resulting in an optimal ZT = 0.067, more than10-fold improvement in comparison to the singlephase filler-based polymer composites. The strategy of integrating nanohybrids consisting of multiple-dimensional heterogeneous nanomaterials into polymers points out a new route towards highperformance organic thermoelectric materials.

\section{Methods}

Materials. Graphite was kindly provided by Asbury Carbons. Fullerene (98\%, Sigma Aldrich) was used without further purification. The sodium chloride ( $>99 \%), \mathrm{N}, \mathrm{N}$ Dimethylformamide (DMF, anhydrous, 99.8\%), phenylhydrazine (97\%), isopropyl alcohol (IPA, 99.7\%), and m-xylene (anhydrous, $\geq 99 \%$ ) were purchased from SigmaAldrich. The nitric acid (fuming, ACS reagent) was purchased from Acros Organics. PEDOT:PSS was (PH 1000) was purchased from Clevios.

Preparation of graphite oxide. Graphene was fabricated through chemical reduction of exfoliated graphite oxide. Graphite oxide was prepared with a modified Brodie's method $^{55}$. Typically, graphite $(10 \mathrm{~g})$, fuming nitric acid $(160 \mathrm{ml})$, and sodium chlorate $(85 \mathrm{~g})$ were mixed at room temperature, but without the subsequent aging used in the Brodie's method. The mixture was stirred for $24 \mathrm{hrs}$, followed by washing, filtration, and cleaning as described by Brodie. Graphite oxide was collected through a precipitation method and evaporation of the solution.

Preparation of chemically reduced graphene oxide (rGO). Graphene nanosheets were achieved by reducing graphite oxide with phenylhydrazine. Typically, $200 \mathrm{mg}$ graphite oxide was dispersed in $20 \mathrm{ml}$ DMF by tip sonication at $50 \mathrm{~W}$ (Misonix sonicator 3000) for 1 hour, resulting in exfoliated graphene oxide. Then $0.5 \mathrm{ml}$ phenylhydrazine ( $35 \mathrm{wt} \%$, Sigma-Aldrich) was added. The mixture was stirred at room temperature for 24 hours, followed by washing with DMF $(500 \mathrm{ml})$ and ethanol $(500 \mathrm{ml})$, respectively. The materials were filtrated and annealed in vacuum oven at $270^{\circ} \mathrm{C}$ overnight, resulting in reduced graphene.

Preparation of $\mathrm{C}_{60} / \mathrm{rGO}$ nanohybrids. The $\mathrm{C}_{60} / \mathrm{rGO}$ nanohybrids were assembled by $\pi-\pi$ conjugation in the liquid-liquid interface. Typically, $\mathrm{C}_{60}$ and rGO were dispersed in $\mathrm{m}$-xylene and IPA, respectively, through ultra-sonication. Then the $\mathrm{rGO} / \mathrm{IPA}(500 \mathrm{mg} / \mathrm{l})$ solution was injected into the $\mathrm{C}_{60} / \mathrm{m}$-xylene solution slowly at a volume ratio of $1: 1$. The color of the interacted interface of two solutions immediately became dark green, indicating the hybridization of $\mathrm{C}_{60}$ and rGO. Subsequently, the interfacial suspension was extracted and transferred into another beaker every $15 \mathrm{~min}$ using a syringe. Five different concentrations $(0.1,0.5,0.75,1$ and $2 \mathrm{mg} / \mathrm{ml}$ ) of $\mathrm{C}_{60} / \mathrm{m}$-xylene solution were used.

Preparation of $\mathrm{C}_{60} / \mathbf{r G O}$-polymer composites. The $\mathrm{C}_{60} / \mathrm{rGO}$-polymer composite was prepared by mixing extracted $\mathrm{C}_{60} / \mathrm{rGO}$ nanohybrids with PEDOT:PSS by gentle stirring, and subsequent drying at $50^{\circ} \mathrm{C}$ overnight. The weight ratio between hybridized nanohybrids and PEDOT:PSS was $3: 7$. The ratio of fullerene to rGO in the nanohybrid was $1: 9,3: 7,5: 5,8: 2,9: 1$, and the samples were named as S1, S2, S3, S4, and S5, respectively.

Characterization. XRD patterns of $\mathrm{C}_{60} / \mathrm{rGO}$ samples were collected by Powder X-ray diffraction (XRD, Rigaku Ultima III diffractometer, $40 \mathrm{kV}, 44 \mathrm{~mA}$, with $\mathrm{Cu} \mathrm{KR}(\lambda=$ $1.54 \AA$ )) was used to study the $\mathrm{C}_{60}$ /graphene samples, and the measurements were taken at a $2 \theta$ range of $5^{\circ} \leq 2 \theta \leq 40^{\circ}$ at room temperature. Powder XRD patterns were analyzed by referring to the International Centre for Diffraction Data (ICDD) powder diffraction file (PDF) database. The UV-Vis spectroscopy was collected with a Perkin Elmer Lambda 1050 spectrometer by placing sample solution in a quartz cuvette. High-resolution transmission electron microscopy (HRTEM, Hitachi H-7650) with an acceleration voltage of $60 \mathrm{kV}$ and scanning electron microscopy (SEM, Hitachi S5000) were employed to characterize the sample morphology. Raman spectra were collected using SENTTERA Raman system model. Electrical conductivity measurements were performed on a SRM probe (Bridge Technology Inc.) by a standard four-point probe method with a Keithley 2400 current source meter and a Keithley 2182A Nanovoltmeter at the room temperature. For the Seebeck coefficient measurements, the thermal voltage was achieved by connecting Keithley 2182A Nanovoltmeter with two identical bare copper wires, which were bonded onto pellets at $20 \mathrm{~mm}$ spacing by silver paste. The temperature gradient was obtained using two surface temperature thermocouples (Omega Inc., controlled by SM325 thermometer data logger). The Seebeck coefficient measurement was calibrated before measurement, and the Seebeck coefficient was calculated with $\mathrm{S}=-\Delta \mathrm{V} / \Delta \mathrm{T}+\mathrm{S}_{\mathrm{Cu}}$ where $\mathrm{S}_{\mathrm{Cu}}$ is $6.5 \mathrm{uV} / \mathrm{K}$ at room temperature ${ }^{56}$. Thermal conductivity was measured by LFA 447 Nanoflash thermal analysis equipment (NETZSCH Instruments) with an error of $\pm 3 \%$. The samples were cold pressed and cut into $6 \mathrm{~mm}$ by $6 \mathrm{~mm}$ cubic sheets. Prior to the thermal conductivity measurement, the sample density was derived from the measured volume and weight. The sample thickness ranged from $0.2 \mathrm{~mm}$ to $0.6 \mathrm{~mm}$, comparable with the reference material. All thermoelectric properties were measured at the room temperature.
1. Dresselhaus, M. S. et al. New directions for low-dimensional thermoelectric materials. Adv. Mater. 19, 1043-1053 (2007).

2. Goldsmid, H. J. Thermoelectric Refrigeration (Plenum, New York, 1964).

3. Snyder, G. J. \& Toberer, E. S. Complex thermoelectric materials. Nat. Mater. 7, 105-114 (2008)

4. Medlin, D. L. \& Snyder, G. J. Interfaces in bulk thermoelectric materials: a review for current opinion in colloid and interface science. Curr. Opin. Colloid. Interface Sci. 14(4), 226-235 (2009).

5. Zebarjadi, M., Esfarjani, K., Dresselhaus, M. S., Ren, Z. F. \& Chen, G. Perspectives on thermoelectrics: from fundamentals to device applications. Energy Environ. Sci. 5(1), 5147-5162 (2012).

6. Hsu, K. F. et al. Cubic $\operatorname{AgPb}(\mathrm{m}) \operatorname{SbTe}(2+\mathrm{m})$ : bulk thermoelectric materials with high figure of merit. Science 303, 818-821 (2004).

7. Hicks, L. D. \& Dresselhaus, M. S. Thermoelectric figure of merit of a onedimensional conductor. Phys. Rev. B 47, 16631-16634 (1993).

8. Venkatasubramanian, R., Siivola, E., Colpitts, T. \& O'Quinn, B. Thin-film thermoelectric devices with high room-temperature figures of merit. Nature 413, 597-602 (2001)

9. Poudel, B. et al. High-thermoelectric performance of nanostructured bismuth antimony telluride bulk alloys. Science 320, 634-638 (2008).

10. Hochbaum, A. I. \& Yang, P. Semiconductor Nanowires for Energy Conversion. Chem. Rev. 110, 527-546 (2010).

11. Moizhes, B. Y. \& Nemchinsky, V. A. in Proc. for the 11th Int. Conf. on Thermoelectrics, University of Texas, Arlington, TX 1992.

12. Humphrey, T. E., O’Dwyer, M. F. \& Linke, H. Power optimization in thermionic devices. J. Phys. D: Appl. Phys. 38, 2051-2054 (2004).

13. Ravich, Y. I. CRC Handbook of Thermoelectrics. (CRC Press, New York, 1995).

14. Cao, Y. Q., Zhu, T. J. \& Zhao, X. B. Thermoelectric $\mathrm{Bi}_{2} \mathrm{Te}_{3}$ nanotubes synthesized by low-temperature aqueous chemical method. J. Alloys Compd. 449, 109-112 (2008).

15. Lee, J. et al. A novel approach for fabrication of bismuth-silicon dioxide core-shell structures by atomic layer deposition. J. Mater. Chem. 19, 7050-7054 (2009).

16. Vineis, C. J., Shakouri, A., Majumdar, A. \& Kanatzidis, M. G. Nanostructured thermoelectrics: big efficiency gains from small features. Adv. Mater. 22, 3970-3980 (2010).

17. Yao, Q., Chen, L. D., Zhang, W. Q., Liufu, S. C. \& Chen, X. H. Enhanced thermoelectric performance of single-walled carbon nanotubes/polyaniline hybrid nanocomposites. ACS Nano 4, 2445-2451 (2010).

18. Zhang, K., Davis, M., Qiu, J. J., Hope-Weeks, L. \& Wang, S. R. Thermoelectric properties of porous multi-walled carbon nanotube/polyaniline core/shell nanocomposites. Nanotechnology 23, 385701 (2012).

19. Yu, C. H., Kim, Y. S., Kim, D. Y. \& Grunlan, J. C. Thermoelectric behavior of segregated-network polymer nanocomposites. Nano Lett. 8, 4428-4432 (2008).

20. Kim, D. Y., Kim, Y. S., Choi, K. W., Grunlan, J. C. \& Yu, C. H. Improved thermoelectric behavior of nanotube-filled polymer composites with poly $(3,4-$ ethylenedioxythiophene) poly(styrenesulfonate). ACS Nano 4, 513-523 (2010).

21. Xiang, J. L. \& Drzal, L. T. Templated growth of polyaniline on exfoliated graphene nanoplatelets (GNP) and its thermoelectric properties. Polymer 53, 4202-4210 (2012).

22. Du, Y. et al. Simultaneous increase in conductivity and Seebeck coefficient in a polyaniline/graphene nanosheets thermoelectric nanocomposite. Synth. Met. 161, 2688-2692 (2012).

23. Zhao, Y., Tang, G. S., Yu, Z. Z. \& Qi, J. S. The effect of graphite oxide on the thermoelectric properties of polyaniline. Carbon 50, 3064-3073 (2012).

24. Kim, G. H., Hwang, D. H. \& Woo, S. I. Thermoelectric properties of nanocomposite thin films prepared with poly(3,4-ethylenedioxythiophene) poly(styrenesulfonate) and graphene. Phys. Chem. Chem. Phys. 14, 3530-3536 (2012).

25. Paloheimo, J., Isotalo, H., Kastner, J. \& Kuzmany, H. Conduction mechanisms in undoped thin-films of $\mathrm{C}_{60}$ and $\mathrm{C}_{60 / 70}$. Synth. Met. 56, 3185-3190 (1993).

26. Sumino, M. et al. Thermoelectric properties of n-type C-60 thin films and their application in organic thermovoltaic devices. Appl. Phys. Lett. 99, 093308 (2011).

27. Cook, B. A., Harringa, J. L. \& Loughin, S. Fullerite additions as a phonon scattering mechanism in p-type Si-20 at.\% Ge. Mat. Sci. Eng. B-Solid. 41, 280-288 (1996).

28. Shi, X. et al. Influence of fullerene dispersion on high temperature thermoelectric properties of $\mathrm{Ba}(\mathrm{y}) \mathrm{Co}(4) \mathrm{Sb}(12)$-based composites. J. Appl. Phys. 102, 103709 (2007).

29. Popov, M. et al. $\mathrm{C}_{60}$-doping of nanostructured Bi-Sb-Te thermoelectrics. Phys. Status Solidi A. 208, 2783-2789 (2011).

30. Vavro, J., Llaguno, M. C., Satishkumar, R., Luzzi, D. E. \& Fischer, J. E. Electrical and thermal properties of C60-filled single-wall carbon nanotubes. Appl. Phys. Lett. 80, 1450-1452 (2002).

31. Zhang, Y. et al. Functionalization of graphene sheets through fullerene attachment. J. Mater. Chem. 21, 5386-5391 (2011).

32. Yang, J. et al. Reduced graphene oxide (rGO)-wrapped fullerene $\left(\mathrm{C}_{60}\right)$ wires. ACS Nano 5, 8365-8371 (2011).

33. Das, M. R. et al. Synthesis of silver nanoparticles in an aqueous suspension of graphene oxide sheets and its antimicrobial activity. Colloid. Surface B. 83, 16-22 (2011).

34. Mao, A. Q. et al. Synthesis of graphene oxide sheets decorated by silver nanoparticles in organic phase and their catalytic activity. J. Phys. Chem. Solids. 73, 982-986 (2012). 
35. Ji, H. X. et al. Controllable preparation of submicrometer single-crystal C-60 rods and tubes trough concentration depletion at the surfaces of seeds. J. Phys. Chem. C 111, 10498-10502 (2007).

36. Alargova, R. G., Deguchi, S. \& Tsujii, K. Stable colloidal dispersions of fullerenes in polar organic solvents. J. Am. Chem. Soc. 123, 10460-10467 (2001).

37. Jeong, J., Kim, W. S., Park, S. I., Yoon, T. S. \& Chung, B. H. Synthesis and characterization of various-shaped C-60 microcrystals using alcohols as antisolvents. J. Phys. Chem. C. 114, 12976-12981 (2010).

38. Wang, S. R., Zhang, Y., Abidi, N. \& Cabrales, L. Wettability and surface free energy of graphene films. Langmuir 25, 11078-11081 (2009).

39. Yoshimoto, S., Amano, J. \& Miura, K. Synthesis of a fullerene/expanded graphite composite and its lubricating properties. J. Mater. Sci. 45, 1955-1962 (2010).

40. Ferrari, A. C. \& Basko, D. M. Raman spectroscopy as a versatile tool for studying the properties of graphene. Nat. Nanotech. 8, 235-246 (2013).

41. Soldano, C., Mahmood, A. \& Dujardin, E. Production, properties and potential of graphene. Carbon 48, 2127-2150 (2010).

42. Stankovich, S. et al. Synthesis of graphene-based nanosheets via chemical reduction of exfoliated graphite oxide. Carbon 45, 1558-1565 (2007).

43. Zhang, X. Y. et al. Synthesis and characterization of a graphene-C- 60 hybrid material. Carbon 47, 334-337 (2009).

44. Yu, D. S., Park, K., Durstock, M. \& Dai, L. M. Fullerene-grafted graphene for efficient bulk heterojunction polymer photovoltaic devices. J. Phys. Chem. Lett. 2, 1113-1118 (2011).

45. Domínguez-Chávez, J. G. et al. Double Molecular Antenna Pyrene-BridgeFullerene C60. The Open Organ. Chem. J. 4, 15-23 (2010).

46. Chubarova, E. V. \& Melenevskaya, E. Y. Analysis of interactions in fullerenesolvent-polymer system by UV-spectroscopy. Fuller. Nanotub. Car. N. 16, 640-643 (2008).

47. Pei, S. F. \& Cheng, H. M. The reduction of graphene oxide. Carbon 50, 3210-3228 (2012).

48. Wassei, J. K. \& Kaner, R. B. Graphene, a promising transparent conductor. Mater. Today 13, 52-59 (2010).

49. Poehler, T. O. \& Katz, H. E. Prospects for polymer-based thermoelectrics: state of the art and theoretical analysis. Energ. Environ. Sci. 5, 8110-8115 (2012).

50. Meng, C. Z., Liu, C. H. \& Fan, S. S. A promising approach to enhanced thermoelectric properties using carbon nanotube networks. Adv. Mater. 22, 535-539 (2010).

51. Humphrey, T. E., O’Dwyer, M. F. \& Linke, H. Power optimization in thermionic devices. J. Phys.: D. Appl. Phys. 38, 2051-2054 (2005).
52. Yu, A. P. et al. Enhanced thermal conductivity in a hybrid graphite nanoplatelet carbon nanotube filler for epoxy composites. Adv. Mater. 20, 4740-4744 (2008).

53. Sumirat, Y. I. \& Shimamura, A. S. Theoretical consideration of the effect of porosity on thermal conductivity of porous materials. J. Porous Mater. 13, 439-443 (2006)

54. Cahill, D. G. et al. Nanoscale thermal transport. J. Appl. Phys. 93, 793-818 (2003).

55. Wang, S. R., Tambraparni, M., Qiu, J. J., Tipton, J. \& Dean, D. Thermal expansion of graphene composites. Macromolecules 42, 5251-5255 (2009).

56. Burkov, A. T., Heinrich, A., Konstantinov, P. P., Nakama, T. \& Yagasaki, K. Experimental set-up for thermopower and resistivity measurements at 100-1300 K. Meas. Sci. Technol. 12, 264-272 (2001)

\section{Acknowledgments}

The authors acknowledge the funding support from National Science Foundation CAREER Award (0953674) and China Scholarship Council (NO.2009663056).

\section{Author contributions}

S.R.W. developed the idea for this work; S.R.W., K.Z. and Y.Z. conceived and designed the experiments; K.Z. and Y.Z. prepared the samples; Y.Z. performed TEM, XRD, and UV-Vis measurements; K.Z. performed Raman characterization and measured the thermoelectric properties; S.R.W., K.Z. and Y.Z. analyzed the results and prepared the manuscript. K.Z. and Y.Z. contributed equally to this work.

\section{Additional information}

Supplementary information accompanies this paper at http://www.nature.com/ scientificreports

Competing financial interests: The authors declare no competing financial interests. How to cite this article: Zhang, K., Zhang, Y. \& Wang, S.R. Enhancing thermoelectric properties of organic composites through hierarchical nanostructures. Sci. Rep. 3, 3448; DOI:10.1038/srep03448 (2013).

(c) (i) $(-)$ This work is licensed under a Creative Commons Attribution-

NonCommercial-NoDerivs 3.0 Unported license. To view a copy of this license, visit http://creativecommons.org/licenses/by-nc-nd/3.0 